\title{
EVALUASI KONDISI LINGKUNGAN DAN SARANA PENYELAMATAN PADA GEDUNG PERKULIAHAN TERHADAP BAHAYA KEBAKARAN
}

\author{
Fadillawaty Saleh ${ }^{1, *)}$, Sinta Rizky Amalia ${ }^{2}$, Hakas Prayuda ${ }^{3}$, Lilis Tiyani ${ }^{4}$ dan Bella Lutfiani Al \\ Zakina $^{5}$ \\ ${ }^{1, *)} J u r u s a n$ Teknik Sipil, Fakultas Teknik, Universitas Muhammadiyah Yogyakarta \\ Email: fadillawaty@umy.ac.id \\ ${ }^{2}$ Jurusan Teknik Sipil, Fakultas Teknik, Universitas Muhammadiyah Yogyakarta \\ Email: sinta.rizky.2014@ft.umy.ac.id \\ ${ }^{3}$ Jurusan Teknik Sipil, Fakultas Teknik, Universitas Muhammadiyah Yogyakarta \\ Email: hakasprayuda@umy.ac.id \\ ${ }^{4}$ Jurusan Teknik Sipil, Fakultas Teknik, Politeknik Negeri Jakarta \\ Email: lilis.tiyani@sipil.pnj.ac.id \\ ${ }^{5}$ Jurusan Teknik Sipil, Fakultas Teknik, Universitas Bojonegoro \\ Email: bellazakina0104@gmail.com
}

\begin{abstract}
Many aspects must be considered in the building's design so that the construction is sturdy and can be used according to its function. An important aspect that is often overlooked is the aspect of fire safety. This study aims to evaluate environmental conditions and safety facilities in buildings against fire hazards. The buildings reviewed are the Postgraduate Building, E6, E7, and F3 Building of the Muhammadiyah University of Yogyakarta. The research method used in this research is a qualitative approach, and the primary data is obtained by direct observation in the field and interviews with the person in charge of the building. This study indicates that the Postgraduate Building, E6, E7, and F3 Building's environmental conditions are not in good condition because each building gets a condition value of $51.67 \% ; 50.56 \% ; 52.22 \%$; and $50 \%$. The rescue facilities in the Postgraduate Building, E6, and E7 Building are good; although there are some shortcomings, the value of the condition of each building is $85.98 \%, 87.41 \%$, and $87.41 \%$. The rescue facility in the F3 Building is quite good, with a condition value of $65.81 \%$.
\end{abstract}

Keywords: environmental condition, safety facilities, fire protection, fire, building

\section{PENDAHULUAN}

Bangunan gedung adalah wujud fisik hasil pekerjaan konstruksi yang menyatu dengan tempat kedudukannya, sebagian atau seluruhnya berada di atas dan/atau di dalam tanah dan/atau air, yang berfungsi sebagai tempat manusia melakukan kegiatannya, baik untuk hunian atau tempat tinggal, kegiatan keagamaan, kegiatan usaha, kegiatan sosial, budaya, maupun kegiatan khusus. Ketika membangun sebuah gedung, banyak aspek yang harus diperhatikan agar gedung tersebut kokoh dan dapat digunakan sesuai fungsinya. Salah satunya adalah aspek keselamatan atau proteksi terhadap bahaya kebakaran atau keadaan darurat. Banyak pemberitaan di media yang melaporkan terjadinya kebakaran pada gedung, penyebabnya bermacammacam, mulai dari hubungan arus pendek listrik, human error, ledakan gas, dan lainlain. Bencana kebakaran menyebabkan banyak dampak negatif seperti kerugian material, lingkungan yang rusak, bahkan dapat memakan korban jiwa. Oleh karena itu, untuk meminimalisasi dampak-dampak yang disebabkan oleh bencana kebakaran pada gedung, maka gedung harus dilengkapi sistem proteksinya.

Ornam (2011) dan Sumardjito (2011) pernah mengkaji kondisi sarana penyelematan jiwa 
pada pusat perbelanjaan terhadap bahaya kebakaran. Hasil dari penelitian tersebut adalah kondisi sistem keselamatan bangunan Mal Kendari tidak aman terhadap bahaya kebakaran. Sukawi dkk (2016) melakukan penelitian untuk mengkaji seberapa jauh kondisi sistem proteksi pemadam kebakaran yang terdapat pada rumah susun UNDIP, dan diperoleh hasil bangunan tersebut cukup aman terhadap bencana kebakaran.

Hesna dkk. (2009) dan Kurniawan dkk. (2014) melakukan penelitian untuk mengevaluasi sarana penyelamatan dan sistem proteksi gedung rumah sakit terhadap bahaya kebakaran. Hasil dari penelitian tersebut adalah rumah sakit yang ditinjau mamiliki sarana penyelamatan dan sistem proteksi yang baik terhadap bahaya kebakaran. Hidayat dkk. (2017) menganalisis keandalan sistem proteksi gedung lawang sewu tehadap bahaya kebakaran, dan diperoleh hasil bahwa bangunan tersebut dalam kondisi cukup baik terhadap bahaya kebakaran.

Wicaksono dkk. (2013) melakukan evaluasi sarana penyelamatan pada gedung industri, dan didapatkan hasil bahwa bangunan tersebut dalam kondisi cukup baik terhadap bahaya kebakaran. Widowati dkk (2017) pernah melakukan penelitian untuk mengevaluasi sarana penyelamatan pada gedung di UNNES. Diperoleh hasil yaitu dari 103 poin yang dikaji, ada sebanyak 41 poin $(39,8 \%)$ terpenuhi dan sesuai dengan peraturan/standar. Sebanyak 12 poin $(11,7 \%)$ telah terpenuhi namun belum sesuai dengan peraturan/standar yang berlaku. Kemudian sebanyak 50 poin $(48,5 \%)$ tidak terpenuhi.

Adiwidjaja (2012) melakukan evaluasi keandalan sistem penyelamatan pada bangunan apartemen terhadap bahaya kebakaran. Hasil penelitian tersebut adalah sistem proteksi pasif bangunan yang ditinjau telah memenuhi persyaratan tetapi kurang lengkap dan sistem proteksi aktifnya kurang memadai. Sedangkan Arrazy dkk. (2014) melakukan penelitian untuk mengevaluasi sistem manajemen keselamatan pada gedung rumah sakit Dr. Sobirin Kabupaten Musi Rawas terhadap bahaya kebakaran. Hasil dari penelitian tersebut adalah sistem manajemen keselamatan pada rumah sakit tersebut sudah baik dan terlaksana.

Berdasarkan Peraturan Menteri Pekerjaan Umum Nomor 25/PRT/M/2008 tentang Pedoman Teknis Penyusunan Rencana Induk Sistem Proteksi Kebakaran, disebutkan bahwa sistem proteksi kebakaran pada bangunan gedung dan lingkungan adalah sistem yang terdiri atas peralatan, kelengkapan dan sarana, baik yang terpasang maupun terbangun pada bangunan yang digunakan baik untuk tujuan sistem proteksi aktif, sistem proteksi pasif, maupun cara-cara pengelolaan dalam rangka melindungi bangunan dan lingkungannya terhadap bahaya kebakaran. Dalam peraturan tersebut, bangunan gedung diharap dilengkapi utilitas, sarana penyelamatan, sistem proteksi aktif dan pasif yang senantiasa dikelola, diawasi serta dipelihara sebagai upaya pencegahan ketika terjadi bencana kebakaran padagedung.

Dari permasalahan di atas, perlu untuk dilakukan evaluasi terhadap beberapa gedung penting di lingkungan Universitas Muhammadiyah Yogyakarta. Penelitian ini berfokus untuk mengevaluasi kondisi lingkungan dan sarana penyelamatan pada 4 (empat) sampel gedung, yaitu gedung pascasarjana, E6, E7, dan F3. Analisis dalam penelitian ini berpedoman pada Peraturan Menteri Pekerjaan Umum Nomor 25/PRT/M/2008 tentang Pedoman Teknis Penyusunan Rencana Induk Sistem Proteksi Kebakaran, serta peraturan pd-t-11-2005 tentang Pemeriksaan Keselamatan Kebakaran Bangunan Gedung. Hasil dari penelitian ini diharapkan dapat menambah wawasan mengenai standar yang baik untuk kondisi lingkungan dan sarana penyelamatan pada gedung-gedung, serta dapat dijadikan referensi kebijakan pimpinan untuk meningkatkan fasilitas gedung Universitas Muhammadiyah Yogyakarta, khususnya untuk gedung yang belum memenuhi standar dalam upaya mengurangi resiko pada saat terjadi kebakaran. 


\section{METODE PENELITIAN}

Penelitian ini dilakukan di gedung pascasarjana, E6, E7, dan F3 Universitas Muhammadiyah Yogyakarta. Pengambilan data primer dilakukan dengan metode observasi langsung ke lapangan dan wawancara dengan pihak pengelola gedung, dengan data yang diambil sebagai berikut ini.

1. Akses dan pasokan air untuk pemadam kebakaran:

a. lingkungan bangunan gedung,

b. akses petugas pemadam kebakaran ke lingkungan, dan

c. akses petugas pemadam kebakaran ke bangunan gedung.

2. Sarana penyelamatan:
a. akses eksit koridor,
b. eksit,
c. keandalan sarana jalan keluar,
d. pintu,
e. ruang terlindung dan proteksi tangga,
f. jalur terusan eksit,
g. kapasitas sarana jalan keluar,
h. pengukuran jarak tempuh eksit,
i. jumlah sarana jalan keluar,
j. susunan sarana jalan keluar,
k. eksit pelepasan,
1. iluminasi sarana jalan keluar,
m. pencahayaan darurat, dan
n. penandaan sarana jalan keluar.

Tabel 1. Tingkat penilaian audit kebakaran (Litbang PU, 2005)

\begin{tabular}{|c|l|c|}
\hline Nilai & \multicolumn{1}{|c|}{ Kesesuaian } & Keandalan \\
\hline$>80-100$ & $\begin{array}{l}\text { Sesuai dengan } \\
\text { persyaratan }\end{array}$ & Baik (B) \\
\hline $60-80$ & $\begin{array}{l}\text { Terpasang tetapi ada } \\
\text { beberapa yang tidak } \\
\text { sesuai persyaratan }\end{array}$ & Cukup (C) \\
\hline$<60$ & $\begin{array}{l}\text { Tidak sesuai sama } \\
\text { sekali }\end{array}$ & Kurang (K) \\
\hline
\end{tabular}

Kemudian kondisi dari tiap komponen yang ditinjau dinilai, diberi bobot dan dievaluasi sesuai dengan hasil pengamatan di lapangan dan wawancara, dengan parameter penilaiannya dirinci pada Tabel 1, sesuai dengan tingkat kesesuaian dan keandalan mengacu pada aturan yang berlaku.

\section{HASIL DAN PEMBAHASAN}

Data yang telah didapat dari hasil observasi langsung di lapangan dan wawancara dengan pihak pengelola gedung di Universitas Muhammadiyah Yogyakarta kemudian hasil tersebut dianalisis untuk memperoleh hasil yang diharapkan sebagai berikut ini.

\section{Akses dan Pasokan Air untuk Pemadam Kebakaran}

Setelah dilakukan observasi, kemudian dilakukan penilaian nilai kondisi dari akses dan pasokan air untuk pemadam kebakaran Gedung Pascasarjana, Gedung E6, E7, dan F3. Pada poin akses dan pasokan air untuk pemadam, ada tiga butir yang dinilai yaitu lingkungan bangunan gedung, akses petugas pemadam kebakaran ke lingkungan, dan hidran halaman, agar diperoleh hasil penilaian setiap gedung sebagai berikut ini.

\section{Gedung Pascasarjana}

Aspek lingkungan bangunan gedung, pada Gedung Pascasarjana sudah tersedia sumber air berupa hidran halaman, dan reservoir air, namun belum tersedia fasilitas komunikasi umum. Jalan lingkungan juga sudah diberi lapis perkerasan dengan paving block, Sedangkan jarak bangunan gedung sudah sesuai dengan persyaratan yang berlaku, sehingga didapatkan skor penilaian sebesar 75\%. Pada aspek akses petugas pemadam kebakaran ke lingkungan, jalan untuk pemadam dalam mencapai lingkungan gedung sudah tersedia, tetapi tidak sesuai dengan persyaratan dan tidak terdapat penandaan pada jalur pemadam kebakaran. Pada jalan akses ke lingkungan gedung terdapat beberapa kendaraan yang terparkir di pinggir jalan akses dan mengurangi dimensi jalan akses. Sehingga didapat skor penilaian sebesar $80 \%$. Poin akses petugas pemadam kebakaran ke bangunan gedung memperoleh skor $0 \%$. Hasil dari penilaian akses dan 
pasokan air untuk pemadam kebakaran pada gedung pascasarjana ditunjukkan Tabel 2.

Tabel 2. Hasil analisis akses dan pasokan air untuk pemadam kebakaran Gd .Pascasarjana

\begin{tabular}{|c|l|c|}
\hline No & \multicolumn{1}{|c|}{ Aspek Penilaian } & $\begin{array}{c}\text { Skor } \\
(\%)\end{array}$ \\
\hline 1 & Lingkungan bangunan gedung & 75 \\
\hline 2 & $\begin{array}{l}\text { Akses petugas pemadam } \\
\text { kebakaran ke lingkungan }\end{array}$ & 80 \\
\hline 3 & $\begin{array}{l}\text { Akses petugas pemadam } \\
\text { kebakaran ke bangunan gedung }\end{array}$ & 0 \\
\hline \multicolumn{2}{|c|}{ Jumlah } & 51,67 \\
\hline
\end{tabular}

\section{Gedung E6}

Poin lingkungan bangunan gedung, pada Gedung E6 sudah tersedia sumber air berupa hidran halaman, dan reservoir air, namun belum memiliki fasilitas komunikasi umum. Jalan lingkungan juga telah dipasang lapis perkerasan dengan paving blcok. Sedangkan jarak bangunan gedung kurang sesuai persyaratan, karena Gedung E6 menyatu dengan gedung fakultas hukum dan Gedung E7, didapatkan skor sebesar $65 \%$.

Poin akses petugas pemadam kebakaran ke lingkungan, jalan untuk pemadam dalam mencapai lingkungan gedung sudah tersedia dan dalam keadaan baik. Namun tidak ada tanda pada jalur untuk pemadam kebakaran. Poin akses petugas pemadam kebakaran ke bangunan gedung memperoleh skor $0 \%$. Ini dikarenakan pada gedung pascasarjana tidak terdapat fasilitas bukaan. Fasilitas ini sangat penting untuk akses masuk petugas pemadam kebakaran ke dalam bangunan gedung ketika terjadi kebakaran. Hasil dari penilaian akses dan pasokan air untuk pemadam kebakaran pada Gedung E6 ditunjukkan pada Tabel 3.

Tabel 3. Hasil analisis akses dan pasokan air untuk pemadam kebakaran Gedung E6

\begin{tabular}{|c|l|c|}
\hline No & \multicolumn{1}{|c|}{ Aspek Penilaian } & $\begin{array}{c}\text { Skor } \\
(\%)\end{array}$ \\
\hline 1 & Lingkungan bangunan gedung & 65 \\
\hline 2 & $\begin{array}{l}\text { Akses petugas pemadam } \\
\text { kebakaran ke lingkungan }\end{array}$ & 86,668 \\
\hline 3 & $\begin{array}{l}\text { Akses petugas pemadam } \\
\text { kebakaran ke bangunan gedung }\end{array}$ & 0 \\
\hline \multicolumn{2}{|c|}{ Jumlah } & 50,56 \\
\hline
\end{tabular}

\section{Gedung E7}

Penilaian pada Gedung E7 hampir sama dengan Gedung E6. Aspek akses petugas pemadam kebakaran ke lingkungan, sudah terdapat hidran halaman, dan reservoir air yang berfungsi baik. Sedangkan pada akses petugas pemadam kebakaran ke bangunan Gedung E7 juga belum tersedianya fasilitas bukaan. Perbedaan ada pada aspek lingkungan bangunan gedung, yaitu Gedung E7 telah memiliki cukup jarak dengan gedung yang lain walaupun bagian utara Gedung E7 menyatu dengan Gedung E6. Hasil dari penilaian akses dan pasokan air untuk pemadam kebakaran pada Gedung E7 ditunjukkan pada Tabel 4.

Tabel 4. Hasil analisis akses dan pasokan air untuk pemadam kebakaran Gedung E7

\begin{tabular}{|c|l|c|}
\hline No & \multicolumn{1}{|c|}{ Aspek Penilaian } & $\begin{array}{c}\text { Skor } \\
(\%)\end{array}$ \\
\hline 1 & Lingkungan bangunan gedung & 70 \\
\hline 2 & $\begin{array}{l}\text { Akses petugas pemadam } \\
\text { kebakaran ke lingkungan }\end{array}$ & 86,66 \\
\hline 3 & $\begin{array}{l}\text { Akses petugas pemadam } \\
\text { kebakaran ke bangunan gedung }\end{array}$ & 0 \\
\hline \multicolumn{2}{|c|}{ Jumlah } & 52,22 \\
\hline
\end{tabular}

\section{Gedung F3}

Penilaian pada Gedung F3 hampir sama dengan penilaian pada gedung yang lain, baik pada aspek akses petugas pemadam kebakaran ke lingkungan, yang telah tersedia fasilitas berupa hidran halaman, dan reservoir air yang dapat berfungsi baik, maupun pada akses petugas pemadam kebakaran ke bangunan gedung, karena belum tersedia fasilitas bukaan. Perbedaan ditemukan pada aspek lingkungan bangunan gedung, yaitu Gedung F3 sudah memiliki cukup jarak dengan gedung yang lain, walaupun agak sulit menentukan jarak tersebut. Perbedaan ini disebabkan karena Gedung F3 dengan gedung yang lain dihubungkan dengan lobi-lobi. Hasil dari penilaian akses dan pasokan air untuk pemadam kebakaran pada Gedung F3 ditunjukkan pada Tabel 5. 
Tabel 5. Hasil analisis akses dan pasokan air untuk pemadam kebakaran Gedung F3

\begin{tabular}{|c|l|c|}
\hline No & \multicolumn{1}{|c|}{ Aspek Penilaian } & $\begin{array}{c}\text { Skor } \\
(\%)\end{array}$ \\
\hline 1 & Lingkungan bangunan gedung & 70 \\
\hline 2 & $\begin{array}{l}\text { Akses petugas pemadam } \\
\text { kebakaran ke lingkungan }\end{array}$ & 80 \\
\hline 3 & $\begin{array}{l}\text { Akses petugas pemadam } \\
\text { kebakaran ke bangunan gedung }\end{array}$ & 0 \\
\hline \multicolumn{2}{|c|}{ Jumlah } & 50 \\
\hline
\end{tabular}

\section{Sarana Penyelamatan}

Setelah dilakukan observasi dan wawancara dengan pihak pengelola gedung, data sarana penyelamatan pada Gedung Pascasarjana, Gedung E6, E7, dan F3 dianalisis, maka dihasilkan skor penilaian rata-rata setiap gedung sebagai berikut ini.

\section{a. Gedung Pascasarjana}

Berdasarkan Tabel 6, sarana penyelamatan pada Gedung Pascasarjana sudah baik dengan skor penilaian $85,98 \%$, karena sebagian besar komponen penilaiannya sudah terpenuhi. Di gedung ini telah tersedia akses eksit yang baik dan terlindungi.

Tabel 6. Hasil analisis sarana penyelamatan Gedung Pascasarjana

\begin{tabular}{|c|l|c|}
\hline No & \multicolumn{1}{|c|}{ Aspek Penilaian } & $\begin{array}{c}\text { Skor } \\
(\%)\end{array}$ \\
\hline 1 & Akses eksit koridor & 100 \\
\hline 2 & Eksit & 86,668 \\
\hline 3 & Keandalan sarana jalan keluar & 100 \\
\hline 4 & Pintu & 100 \\
\hline 5 & $\begin{array}{l}\text { Ruang terlindungi dan proteksi } \\
\text { tangga }\end{array}$ & 60,004 \\
\hline 6 & Jalan terusan eksit & 100 \\
\hline 7 & Kapasitas sarana jalan keluar & 100 \\
\hline 8 & Pengukuran jarak tempuh eksit & 100 \\
\hline 9 & Jumlah sarana jalan keluar & 100 \\
\hline 10 & Susunan sarana jalan keluar & 100 \\
\hline 11 & Eksit pelepasan & 95 \\
\hline 12 & Iluminasi jalan keluar & 90 \\
\hline 13 & Pencahayaan darurat & 0 \\
\hline 14 & Penandaan sarana jalan keluar & 72 \\
\hline \multicolumn{2}{|l|}{ Jumlah } & 85,98 \\
\hline
\end{tabular}

Semua eksit yang ada pada gedung ini berakhir langsung pada bagian luar gedung atau bagian luar dari eksit pelepasan. Tetapi di dalam tangga darurat terdapat barang-barang yang berpotensi mengganggu ketika dalam keadaan darurat. Pada tangga darurat juga belum tersedia penandaan level lantai. Pencahayaan pada gedung ini sudah baik, namun belum tersedia fasilitas pencahayaan darurat baik pada tangga darurat maupun pada koridor gedung. Hasil dari penilaian sarana penyelamatan pada gedung ini terlihat pada Tabel 6.

\section{b. Gedung E6}

Berdasarkan Tabel 7, sarana penyelamatan pada Gedung E6 sudah baik, karena sebagian besar komponennya sudah terpenuhi, dengan skor penilaian rata-rata dari keseluruhan komponen sebesar $87,41 \%$.

Tabel 7. Hasil analisis sarana penyelamatan Gedung E6

\begin{tabular}{|c|l|c|}
\hline No & \multicolumn{1}{|c|}{ Aspek Penilaian } & $\begin{array}{c}\text { Skor } \\
(\%)\end{array}$ \\
\hline 1 & Akses eksit koridor & 100 \\
\hline 2 & Eksit & 100 \\
\hline 3 & Keandalan sarana jalan keluar & 100 \\
\hline 4 & Pintu & 100 \\
\hline 5 & $\begin{array}{l}\text { Ruang terlindungi dan proteksi } \\
\text { tangga }\end{array}$ & 66,67 \\
\hline 6 & Jalan terusan eksit & 100 \\
\hline 7 & Kapasitas sarana jalan keluar & 100 \\
\hline 8 & Pengukuran jarak tempuh eksit & 100 \\
\hline 9 & Jumlah sarana jalan keluar & 100 \\
\hline 10 & Susunan sarana jalan keluar & 100 \\
\hline 11 & Eksit pelepasan & 95 \\
\hline 12 & Iluminasi jalan keluar & 90 \\
\hline 13 & Pencahayaan darurat & 0 \\
\hline 14 & Penandaan sarana jalan keluar & 72 \\
\hline & $\quad$ Jumlah & 87,05 \\
\hline
\end{tabular}

Pada Gedung E6 sudah tersedia akses eksit yang baik, dan terlindungi. Semua eksit pada Gedung E6 berakhir langsung pada bagian luar dari eksit pelepasan. Semua sarana jalan menuju eksit pun sudah dilengkapi dengan sistem spingkler otomatis. Tangga darurat juga sudah tersedia pada gedung ini, dengan jalur yang menerus, dan terlindungi. Namun belum tersedia penandaan pada tiap lantainya yang menunjukkan tingkatan lantai. Pencahayaan pada gedung E6 dalam keadaan 
baik, namun belum terdapat fasilitas pencahayaan darurat baik pada tangga darurat maupun pada koridor sarana jalan keluar. Hasil dari penilaian sarana penyelamatan pada Gedung E6 ditunjukkan pada Tabel 7.

\section{c. Gedung E7}

Berdasarkan Tabel 8, sarana penyelamatan pada Gedung E7 sudah baik, karena sebagian besar komponen sudah terpenuhi, dengan skor penilaian rata-rata sebesar $87,41 \%$. Sarana penyelamatan pada Gedung E7 hampir sama dengan Gedung E6, karena gedung ini dibuat bersamaan dan telah tersedia akses eksit yang baik, dan terlindungi. Semua eksit pada Gedung E7 berakhir langsung pada bagian luar eksit pelepasan. Semua sarana jalan menuju eksit sudah dilengkapi dengan sistem spingkler otomatis. Tangga darurat juga sudah tersedia, jalurnya menerus, dan terlindungi, namun belum tersedia penandaan yang menunjukkan tingkatan lantai pada tiap lantainya. Pencahayaan pada Gedung E7 sudah baik, namun belum terdapat fasilitas pencahayaan darurat baik pada tangga darurat maupun koridor sarana jalan keluar. Hasil dari penilaian sarana penyelamatan pada Gedung E7 ditunjukkan pada Tabel 8.

Tabel 8. Hasil analisis sarana penyelamatan Gedung E7

\begin{tabular}{|c|l|c|}
\hline No & \multicolumn{1}{|c|}{ Aspek Penilaian } & $\begin{array}{c}\text { Skor } \\
(\%)\end{array}$ \\
\hline 1 & Akses eksit koridor & 100 \\
\hline 2 & Eksit & 100 \\
\hline 3 & Keandalan sarana jalan keluar & 100 \\
\hline 4 & Pintu & 100 \\
\hline 5 & $\begin{array}{l}\text { Ruang terlindungi dan proteksi } \\
\text { tangga }\end{array}$ & 66,67 \\
\hline 6 & Jalan terusan eksit & 100 \\
\hline 7 & Kapasitas sarana jalan keluar & 100 \\
\hline 8 & Pengukuran jarak tempuh eksit & 100 \\
\hline 9 & Jumlah sarana jalan keluar & 100 \\
\hline 10 & Susunan sarana jalan keluar & 100 \\
\hline 11 & Eksit pelepasan & 95 \\
\hline 12 & Iluminasi jalan keluar & 90 \\
\hline 13 & Pencahayaan darurat & 0 \\
\hline 14 & Penandaan sarana jalan keluar & 72 \\
\hline \multicolumn{2}{|c|}{ Jumlah } & 87,05 \\
\hline
\end{tabular}

\section{d. Gedung F3}

Berdasarkan Tabel 9, sarana penyelamatan pada Gedung F3 sudah cukup baik, karena sebagian besar komponen sudah terpenuhi,dengan skor penilaian rata-rata dari keseluruhan komponen adalah sebesar $65,81 \%$. Pada Gedung F3 sudah tersedia akses menuju eksit yang baik, namun tidak terlindungi. Semua eksit pada Gedung F3 berakhir langsung pada bagian luar dari eksit pelepasan. Semua sarana jalan menuju eksit belum dilengkapi dengan sistem spingkler otomatis, hanya beberapa ruangan pada lantai 2, 3, dan 4 yang dipasang sistem spingkler.

Tangga darurat tidak tersedia pada gedung ini, padahal menurut peraturan yang berlaku tangga darurat harus ada pada gedung yang melayani lebih dari 3 lantai. Tangga yang tersedia pada gedung ini juga belum tersedia penandaan pada tiap lantainya yang menunjukkan tingkatan lantai. Pencahayaan pada Gedung F3 sudah cukup baik, namun belum terdapat fasilitas pencahayaan darurat pada tangga maupun koridor sarana jalan keluar gedung. Hasil dari penilaian sarana penyelamatan pada Gedung F3 ditunjukkan pada Tabel 9.

Tabel 9. Hasil analisis sarana penyelamatan Gedung F3

\begin{tabular}{|c|c|c|}
\hline No & Aspek Penilaian & $\begin{array}{l}\text { Skor } \\
(\%)\end{array}$ \\
\hline 1 & Akses eksit koridor & 100 \\
\hline 2 & Eksit & 0 \\
\hline 3 & Keandalan sarana jalan keluar & 100 \\
\hline 4 & Pintu & 100 \\
\hline 5 & $\begin{array}{l}\text { Ruang terlindungi dan proteksi } \\
\text { tangga }\end{array}$ & 0 \\
\hline 6 & Jalan terusan eksit & 53,328 \\
\hline 7 & Kapasitas sarana jalan keluar & 100 \\
\hline 8 & Pengukuran jarak tempuh eksit & 100 \\
\hline 9 & Jumlah sarana jalan keluar & 100 \\
\hline 10 & Susunan sarana jalan keluar & 90 \\
\hline 11 & Eksit pelepasan & 70 \\
\hline 12 & Iluminasi jalan keluar & 80 \\
\hline 13 & Pencahayaan darurat & 0 \\
\hline 14 & Penandaan sarana jalan keluar & 28 \\
\hline \multicolumn{2}{|r|}{ Jumlah } & 65,81 \\
\hline
\end{tabular}


Berdasarkan hasil evaluasi pada Gedung Pascasarjana, E6, E7, dan F3, diperoleh hasil dalam bentuk grafik seperti yang ditunjukkan Gambar 1. Assessment pada bangunan gedung tarhadap sarana penyelamatan sudah banyak dilakukan oleh beberapa peneliti terdahulu dengan mengacu pada berbagai standar yang ada. Pada penelitian ini hanya menganalisis kondisi lungkungan gedung dan sara penyelamatan yang ada pada gedung untuk mencegah dan membantu proses evakuasi saat terjadi kebakaran. Widowati dkk (2015) juga pernah melakukan assessmen sarana penyelamatan pada gedung perkuliahan, pada hasil penelitian tersebut menunjukkan hasil sebanyak 39,8\% memenuhi standar yang berlaku sedangkan pada penelitian ini, dari keseluruhan gedung menunjukkan hasil lebih dari $80 \%$ memenuhi standar yang berlaku kecuali pada Gedung F3. Meskupun begitu, perlu dilakukan peningkatan pada sarana penyelamatan, sehingga mencapai lebih dari $95 \%$.

- Akses dan Pasokan Air untuk Pemadaman Kebakaran a Sarana Penyelamatan

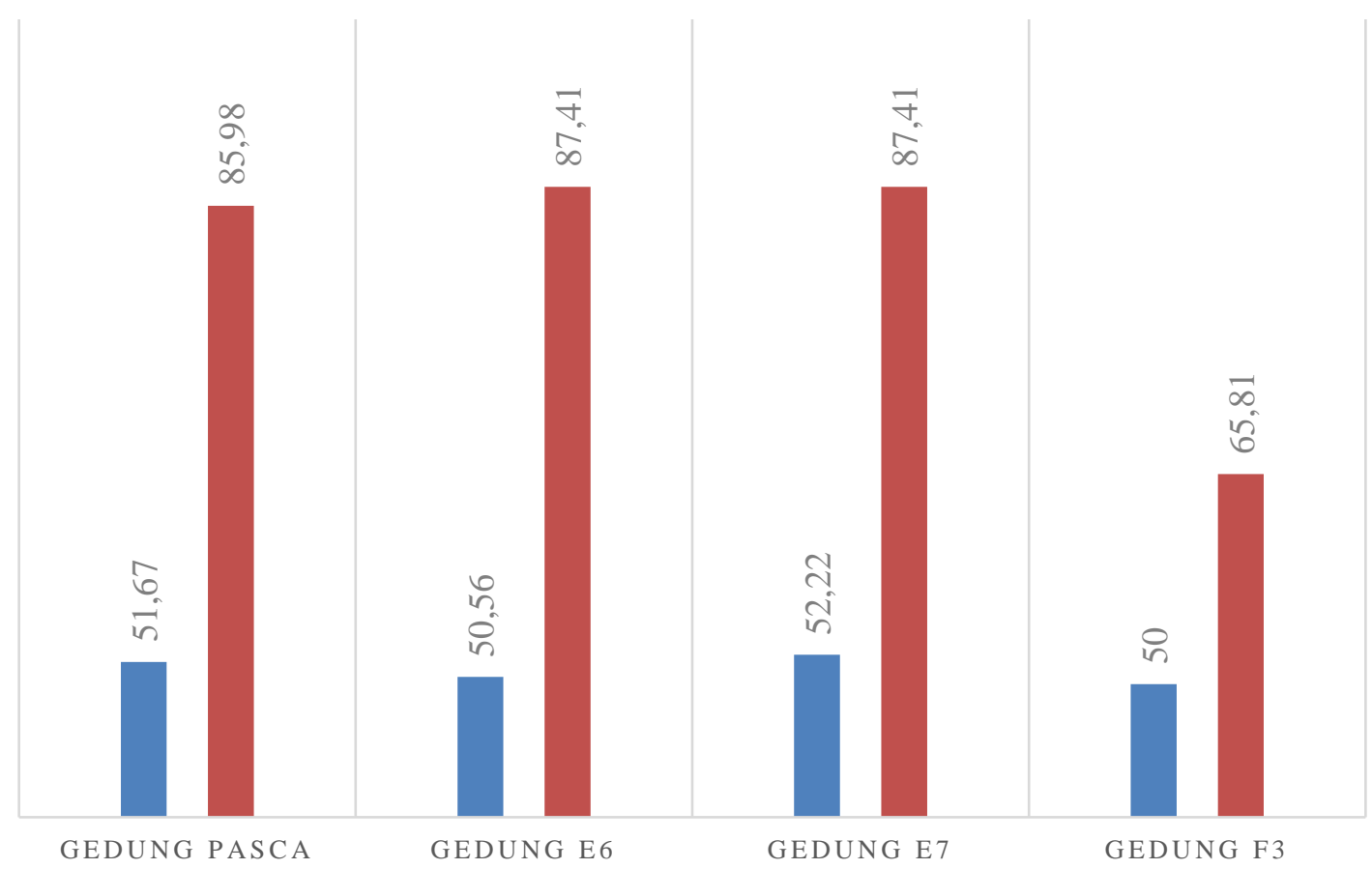

Gambar 1. Kondisi lingkungan dan sarana penyelamatan Gedung Pascasarjana, Gedung E6, E7, dan F3

\section{Evaluasi Hasil Penelitian}

Berdasarkan hasil analisis dari data yang didapat pada Gedung pascasarjana, E6, E7 dan F3, diperoleh bahwa untuk keempat gedung yang ditinjau termasuk dalam kategori kurang baik untuk aspek akses dan pasokan air untuk pemadaman kebakaran. Oleh karena itu, ada beberapa saran yang diusulkan agar kategori gedung tersebut naik satu tingkat lebih baik.

Gedung Pascasarjana dan F3 sebaiknya dilengkapi dengan fasilitas komunikasi umum serta mensterilkan jalur akses menuju gedung dari kendaraan yang terparkir di jalur akses. Pada Gedung E6 sebaiknya dilengkapi dengan fasilitas komunikasi umum serta 
mensterilkan halaman gedung dari kendaraan yang terparkir. Sedangkan untuk Gedung E7 cukup dengan menambahkan fasilitas komunikasi umum.

\section{KESIMPULAN}

1. Kondisi lingkungan pada Gedung pascasarjana, E6, E7, dan F3 termasuk dalam kondisi yang kurang baik, dengan masing-masing gedung memperoleh nilai kondisi $51,67 \%$; 50,56\%; 52,22\%; dan $50 \%$. Sedangkan untuk sarana penyelamatan pada Gedung pascasarjana, Gedung E6 dan E7 sudah baik walau ada beberapa kekurangan dengan nilai kondisi masing-masing $85,98 \%$; 87,41\%; dan $87,41 \%$. Sedangkan sarana penyelamatan pada Gedung F3 cukup baik dengan nilai kondisi $65,81 \%$.

2. Saran perbaikan yang diusulkan agar gedung yang tergolong dalam kondisi kurang dapat naik satu tingkat lebih baik adalah untuk Gedung Pascasarjana dan Gedung F3 sebaiknya dilengkapi dengan fasilitas komunikasi umum serta mensterilkan jalur akses menuju gedung dari kendaraan yang terparkir di jalur akses. Pada Gedung E6 sebaiknya dilengkapi dengan fasilitas komunikasi umum serta mensterilkan halaman gedung dari kendaraan yang terparkir. Sedangkan untuk Gedung E7 cukup dengan menambahkan fasilitas komunikasi umum.

\section{DAFTAR PUSTAKA}

Adiwidjaja, R. (2012). "Studi Tingkat Keandalan Sistem Proteksi Kebakaran pada Bangunan Apartemen (Studi Kasus Apartemen di Surabaya)". Journal of Architecture and Built Environment. 39 (1), 15-22.

Arrazy, S., Sunarsih, E., dan Rahmiwati, A. (2014). "Penerapan Sistem Manajemen Keselamatan Kebakaran di Rumah Sakit
Dr. Sobirin Kabupaten Musi Rawas Tahun 2013". Jurnal Ilmu Kesehatan Masyarakat. 5, 103-111.

Badan Litbang PU. (2005). "Pemeriksaan Keselamatan Kebakaran Bangunan Gedung”. Jakarta.

Hesna, Y., Hidayat B., dan Suwanda, S. (2009). "Evaluasi Penerapan Sistem Keselamatan Kebakaran pada Bangunan Gedung Rumah Sakit Dr. M. Djamil Padang". Jurnal Rekayasa Sipil. 5(2), 65-76.

Hidayat, D. A., Suroto., Kurniawan, B. (2017). "Evaluasi Keandalan Sistem Proteksi Kebakaran Ditinjau dari Sarana Penyelamatan dan Sistem Proteksi Pasif Kebakaran di Gedung Lawang Sewu Semarang". Jurnal Kesehatan Masyarakat. 5 (5), 134-146.

Kurniawan, P. A., Sugiyarto., dan Laksito, B. (2014). "Evaluasi Penerapan Sistem Proteksi Kebakaran pada Bangunan Rumah Sakit (Studi Kasus RS. Ortopedi Prof. Dr. R Soeharso Surakarta)". EJurnal Matriks Teknik Sipil. 824-832.

Ornam, Kurniati. (2011)." Kajian Tentang Penerapan Sistem Keselamatan Jiwa Terhadap Bahaya Kebakaran pada Perancangan Pusat Perbelanjaan Mal Mandonga Kendari”. Unity Jurnal Arsitektur. 1(2), 87-95.

Peraturan Menteri Pekerjaan Umum. (2008). "Persyaratan Teknis Sistem Proteksi Kebakaran pada Bangunan Gedung dan Lingkungan". Jakarta.

Sukawi., Hardiman, G., DA, N. A., dan P, Z. A. (2016). "Evaluasi Sistem Proteksi Kebakaran pada Bangunan Rumah Susun (Studi Kasus: Rusunawa UNDIP)". Undip E-Journal System Portal. 16 (1), 35-42.

Sumardjito. (2011). "Kajian Terhadap Kelayakan Sarana Emergency Exit pada Bangunan Pusat Perbelanjaan di Yogyakarta". Jurnal Pendidikan Teknologi dan Kejuruan. 20 (1), 89-116. 
Wicaksono, R. R., dan Ernawati, M. [2013]. "Evaluasi Sarana Evakuasi Kebakaran di Industri Karung Sidoarjo". The Indonesian Journal of Republic Health. 10 (1), 44-55.

Widowati, E., Koesyanto, H., Wahyuningsih, A. S., dan Sugiharto. (2017). "Analisis Keselamatan Gedung Baru F5 Universitas Negeri Semarang Sebagai Upaya Tanggap Keadaan Darurat". Unnes Journal of Public Health. 6 (2), 101-106. 